University of Nebraska - Lincoln

DigitalCommons@University of Nebraska - Lincoln

\title{
Genetic and evolutionary considerations of the Chronic Wasting Disease - Human species barrier
}

Robert M. Zink

University of Nebraska - Lincoln, rzink2@unl.edu

Follow this and additional works at: https://digitalcommons.unl.edu/natrespapers

Part of the Natural Resources and Conservation Commons, Natural Resources Management and Policy Commons, Other Environmental Sciences Commons, Veterinary Infectious Diseases Commons, and the Veterinary Preventive Medicine, Epidemiology, and Public Health Commons

Zink, Robert M., "Genetic and evolutionary considerations of the Chronic Wasting Disease - Human species barrier" (2020). Papers in Natural Resources. 1417.

https://digitalcommons.unl.edu/natrespapers/1417

This Article is brought to you for free and open access by the Natural Resources, School of at DigitalCommons@University of Nebraska - Lincoln. It has been accepted for inclusion in Papers in Natural Resources by an authorized administrator of DigitalCommons@University of Nebraska - Lincoln. 


\title{
Genetic and evolutionary considerations of the Chronic Wasting Disease - Human species barrier
}

\author{
Robert M. Zink \\ School of Natural Resources, School of Biological Sciences, Nebraska State \\ Museum, University of Nebraska-Lincoln, Lincoln, NE 68503, United States \\ of America; Email Rzink2@unl.edu.
}

\begin{abstract}
Transmissible spongiform encephalopathies can jump species barriers. In relatively few cases is the possible route of transmission thought to be known, mostly involving humans, cattle and sheep. It is thought that sheep might be the cause of Bovine Spongiform Encephalopathy (BSE) and Chronic Wasting Disease (CWD) in cervids, and that humans might have gotten prion disease (e.g., vCJD) from eating meat from BSE+ cows. A looming societal question is whether humans will acquire a prion disease from ingesting prions from CWD+ deer. On an evolutionary tree of the PRNP gene in mammals, deer, sheep and cow are relatively closely related, whereas these three species are relatively distant from humans. If a prion disease jumped the species barrier from cow to humans, the phylogenetic gap from deer to humans is no greater, and sheer evolutionary distance alone cannot explain a CWD species barrier in humans. Aspects of the PRNP gene were compared among these species to search for genetic differences that might influence the permeability of the species barrier. Human prion disease has been associated with having more than four copies of the octarepeat unit (PHGGGWG), whereas deer, sheep and cow all have three copies. Two amino acid positions in the metal-binding region (96 and 97) have been implicated in species barriers (Breydo and Uversky, 2011), whereas no variation was detected in white-tailed deer and mule deer with and without CWD,
\end{abstract}

Published in Infection, Genetics and Evolution 84 (2020), 104484.

doi:10.1016/j.meegid.2020.104484

Copyright (C) 2020 Elsevier B.V. Used by permission.

Submitted 31 January 2020; revised 20 July 2020; accepted 23 July 2020; published 27 July 2020. 
or in black-tailed deer, Key deer or Coues deer. Four out of 10 differences between deer and human in the $\beta 2-\alpha 2$ loop might preclude CWD prions from converting human PrPC to PrPSc because of disruption of a steric zipper. The reasons for a CWD species barrier between deer and humans, if there is one, is still unresolved.

Keywords: Prions, White-tailed deer, Transmissible spongiform encephalopathies, Phylogeny, Disease transmission, Disease evolution

\section{Introduction}

The current rapid increase in the incidence and geographic spread of Chronic Wasting Disease (CWD) in North American cervids has implications for at least two levels of societal concern. First, a reduction in the number of people participating in deer hunting could result in a major economic consequences. In 2016, the hunting industry generated more than 23 billion dollars for equipment and travel, which yielded nearly 3.5 billion yearly in federal, state and local taxes (https://wsfrprograms.fws.gov/Subpages/NationalSurvey/National Survey.htm ). A second concern is that a large number of deer are consumed annually in the U.S., Mexico and Canada. Will the growing number of people exposed to meat from infected deer result in CWD crossing the species barrier to humans and eliciting a transmissible spongiform encephalopathy (TSE), either vCJD or something new, much like bovine spongiform encephalopathy is assumed to have done (Osterholm et al., 2019; Sakudo, 2019)? The remainder of this paper concerns the threat of CWD to humans from a genetic and evolutionary perspective.

Numerous papers have explored the possibility of humans contracting a TSE by ingesting prions from CWD positive (CWD+) white-tailed deer (Odocoileus virginianus) or mule deer (O. hemionus). An inadvertent experiment is underway involving 81 people who unknowingly consumed venison from a CWD+ white-tailed deer in New York in 2005 (Garruto et al., 2008; Olszowy et al., 2014). Because a deer does not exhibit clinical signs of CWD until the later stages of infection, it is a virtual certainty that many people have ingested some level of prions by consuming what appeared to be a healthy deer (Osterholm et al., 2019), as in the New York case. Even testing cannot rule out infection in the early stages of disease progression. For example, the USDA ELISA minimum standard OD-value for assigning infection 
is 0.035 , whereas some state agencies set a limit of 0.1 before declaring a deer to be positive for CWD. Thus, it is unclear when during the course of infection a deer has a high enough titer of prions to be infectious to other deer or humans. It would be highly unlikely that a late-stage CWD+ deer would be eaten, because it would appear obviously abnormal, but otherwise normal, healthy appearing individuals can be infected and not recognized as diseased. The CDC recommends against eating a deer at any stage of infection.

There are as yet no cases in which a human is known to have contracted a TSE from eating deer meat (Waddell et al., 2018), although given the lag time for other similar diseases, such as mad cow disease, it is perhaps premature to conclude that CWD will not cross the species barrier to humans (Osterholm et al., 2019). A study in which macaque monkeys (Macaca fascicularis) were fed large quantities of highly concentrated CWD+ meat produced conflicting results, although it is possible that some form of TSE was generated in some of the monkeys (Race et al., 2018a).

One of the difficulties in judging human exposure to CWD is knowing how long, and in what frequency, CWD has been in the deer herd. Transmissible spongiform encephalopathies (TSEs) are widespread in animals (see below), which reveals that TSEs originated early in animal evolutionary history. Recent findings suggest a major increase in the incidence and geographic spread of CWD in North America. For example, the incidence of CWD in some areas has gone from less than $2 \%$ to almost $60 \%$ in adult male white-tailed deer between 2002 and 2016 (https://dnr.wi.gov/topic/wildlifehabitat/documents/swsauk. pdf ). Thus, perhaps only in the past decade has the number of CWD+ deer reached sizeable enough frequencies to pose a threat to humans. Rongyan et al. (2008) noted that scrapie has been endemic in the United Kingdom for more than 200 years and yet has not crossed the species barrier into humans.

\section{CWD and the PRNP locus: phylogenetic perspective}

A central focus of studies of TSE is the PRNP gene. This gene is widespread in vertebrate animals (Calzolai et al., 2005; Rivera-Milla et al., 2006; Rongyan et al., 2008) and is the ultimate basis of TSEs. The 
prevailing hypothesis is that PrPC misfolds and by coming into contact with other PrPC causes them to misfold and become infectious PrPSc. The ever-expanding population of PrPSc forms amyloid plaques especially in the central nervous system and results in inevitable death. Animals acquire infectious prions from several possible sources: spontaneously (Osterholm et al., 2019), through heredity, in utero (Selariu et al., 2015), from contaminated food sources (Mathiason et al., 2006), via the environment (Nichols et al., 2015; VerCauteren et al., 2012), or via copulation (Kramm et al., 2019).

One way to explore whether CWD might cross species boundaries is to adopt an evolutionary or phylogenetic perspective. Cullingham et al. (2020) constructed a phylogenetic tree using a single mitochondrial gene (Cyt $b$ ) for species susceptible (deer, moose, elk, caribou) and resistant (cow, raccoon, mustelids, cat, canid, human, macaque, squirrel monkey, hamster) to CWD. Mapping the presence or absence of CWD+ susceptibility on the tree yielded an estimate of the frequency of CWD susceptibility at ancestral nodes, which suggested potential susceptibility for pronghorn, bighorn sheep, and mountain goat, but not for bison. In my opinion, these conclusions could be compromised because the mapping method only describes the phylogenetic distribution of the states and does not yield probabilities or likelihoods of species acquiring CWD. Furthermore, the use of a single gene and a small sampling of species limits inferences about the reconstruction of the ancestral presence or absence of CWD. In particular, to map the evolution of CWD requires using the sister group of cervids, whereas Cullingham et al. (2020) used a small set of more distantly unrelated species.

A phylogenetic analysis of the PRNP gene and 20 independent nuclear encoded loci in 102 species of mammals (Buchanan and Zink 2020) suggests that TSEs appear to have arisen multiple times in the recent evolutionary history of mammals (Fig. 1). The arrows on the tree illustrate ideas about transmission of TSEs across species boundaries. It is thought that BSE is derived from scrapie (Harrathi et al., 2019), although some analyses suggest otherwise (e.g., Capobianco et al., 2007; Konold et al., 2013). Human variant CJD is likely derived from BSE (Harrathi et al., 2019). An often repeated hypothesis is that mule deer co-penned with sheep in the mid-1967 in Colorado resulted in scrapie jumping the species barrier and causing prion disease in 

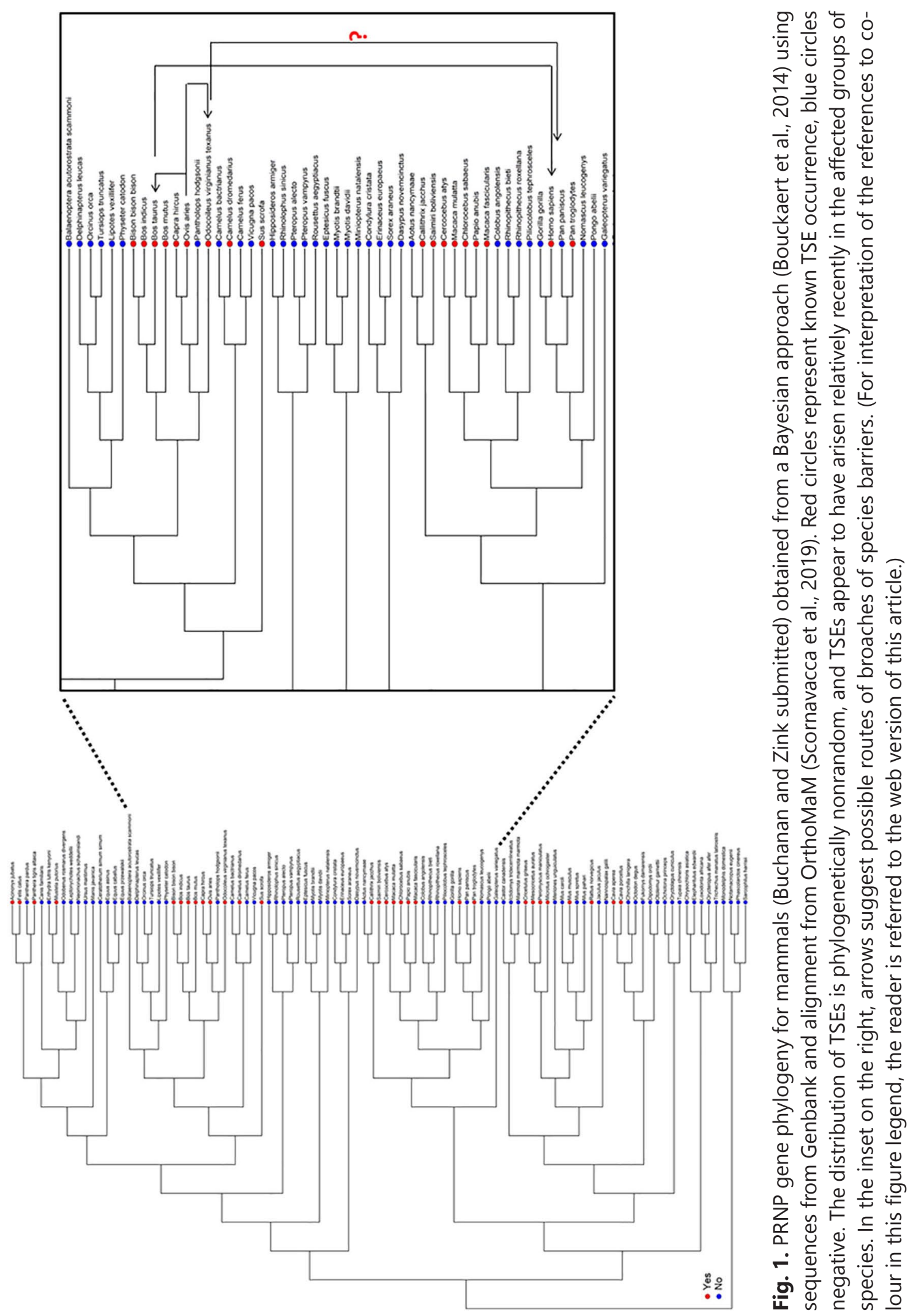
Table 1 Net average number of amino acid differences between species.

\begin{tabular}{lcccc} 
& Mule deer & Human & Cow & Sheep \\
\hline Mule deer & 21 & & & \\
Human & 6 & 19 & & \\
Cow & 4 & 21 & 6 & 4 \\
Sheep & 21 & 6 & 4 \\
White-tailed deer & 0.1 & & & \\
\hline
\end{tabular}

mule deer, a TSE disease later termed Chronic Wasting Disease (Williams and Young, 1980). Interestingly, the link between sheep and deer has been all but abandoned, despite the fact that farmed sheep and wild deer co-exist in many agricultural areas. A remaining question is why humans have not acquired a TSE-like disease from cervids (Waddell et al., 2018). Is it simply a function of insufficient time of exposure of enough people to CWD+ venison, or are there genetic factors that provide a species barrier?

Deer, sheep and bovines are relatively closely related, whereas all are phylogenetically distant from humans (Fig. 1). In fact, these two groups of species are phylogenetically as distant as any two mammals on the tree because the branch connecting them goes through the base of the tree (exclusive of monotremes). This distance is reflected in the amino acid differences between these taxa. Cow, sheep and deer all differ on average by 4-6 amino acid substitutions at the PRNP locus, whereas these three taxa differ from humans by 21 (Table 1). If the PRNP sequence in deer differed substantially from cow, it might underlie an apparent inability of CWD to infect humans (Sakudo, 2019); however, this is not the case. Thus, sheer evolutionary distance alone cannot explain a CWD species barrier between humans and cervids.

\section{Comparisons of specific amino acids, octarepeats units, and the $\beta 2-\alpha 2$ loop}

Apart from phylogenetic distance, I compared genetic characteristics of the PRNP gene among sheep, cow, deer and human. Most mammals have three or four copies of a repeat unit PHGGGWG (Stevens et al., 2009), which according to a protein model (not shown) for whitetailed deer constructed with PHYRE2 (Kelley et al., 2015), occur in the 
extracellular matrix and not in the membrane. In general, sheep, cow and deer all have three tandem repeats of PHGGGWGQ, flanked by sequences PHGGGGWGQ (5') and PQGGGGWGQ (3'), whereas humans typically have four tandem repeats of PHGGGWGQ, with PQGGGGWGQ also at the $3^{\prime}$ end, but a different motif at the $5^{\prime}$ end. Extra copies of the tandem octarepeat unit are often observed in patients with vCJD (Asante et al., 2015), whereas the relationship of variation in the number of repeats to prion disease is unknown for most animals. In 204 white-tailed deer and 136 mule deer of known CWD status (50\% of each were $\mathrm{CWD}+$ ) from Nebraska, 15 white-tailed deer from Minnesota, 7 white-tailed deer from New York, 15 Key deer from Florida $(O$. v. clavium), 35 Coues deer from Arizona (O. v. couesi), and 21 blacktailed deer ( $O . h$. columbianus, $O$. h. sitkensis), all were homozygous for 3 tandemly repeated copies of PHGGGWGQ (Zink et al. 2020). Therefore, variation in the number of octarepeats apparently plays no role in CWD expression in these North American cervids. In the sample of 102 mammals in Fig. 1, the number of repeats also does not differ between taxa with and without TSEs (pers. obs.).

Certain alleles/genotypes at the PRNP locus provide some degree of lessened susceptibility to TSEs. In sheep, the amino acid positions in the PRNP gene relevant to scrapie resistance are $136(\mathrm{~A} / \mathrm{V}), 154(\mathrm{R} / \mathrm{H})$ and $171(\mathrm{Q} / \mathrm{R} / \mathrm{H})$, with the $136 \mathrm{~A} 154 \mathrm{R} 171 \mathrm{R}$ genotype conferring complete or nearly complete resistance (Hagenaars et al., 2018). At the seven amino acid positions implicated in TSE resistance in both sheep and deer, genotypes are often shared: Q(95), G(96), A(116), A(136), R (154), Q(226), Q(171). The 95H allele results in the greatest delay to the onset of clinical CWD symptoms in white-tailed deer (Johnson et al., 2011; Haley et al., 2019), and an F at position 225 in mule deer ( $O$. hemionus) is thought to provide some resistance (Jewell et al., 2005; Slapšak et al., 2019). Deer lack the mutation at position 171 that renders sheep immune (or nearly so) to scrapie, although Vázquez-Miranda and Zink (2020) noted that a single mutation in the cervid PRNP could produce the amino acid at position 171 that provides resistance in sheep. Elk (Cervus elaphus nelsoni) that are MM132 more rapidly attain CWD infections whereas those animals with LL132 have delayed susceptibility (Moore et al., 2020). In cattle, none of the known PRNP polymorphisms are linked to altered susceptibility to Bovine Spongiform Encephalopathy (BSE), whereas deletions in the promoter do 
increase BSE incidence (Haase et al., 2007). Zink et al. (2020) found no relationship between deletions in the promoter and the incidence of CWD in mule deer and white-tailed deer from Nebraska.

It is relevant to consider genetic differences between human and cervid PRNP. A mutation at amino acid position 127 in humans is thought to prevent kuru, whereas a methionine/valine heterozygote at position 129 provides partial protection against sporadic, acquired, and some inherited prion diseases (Lee et al., 2001; Asante et al., 2015). Humans with VCJD thought to be precipitated via exposure to BSE are usually homozygous for methionine at position 129. Deer, cow and sheep share the same two amino acids in general at 127 and 129. Many other AA positions are linked with human prion diseases (Race et al., 2018b) and other genetic factors have been implicated (Mead et al., 2011). The question is whether cervid prions obtained from consuming CWD+ meat might corrupt human PrPC. Furthermore, do protein products produced from different cervid PRNP genotypes, such as Q95H vs G95G, have differential ability to induce prion disease in humans (Hwang et al., 2020)?

At amino acid sites thought to be associated with CWD resistance in deer (Table 2), deer and bovines are equidistant from humans. The human wild type genotype differs from deer and cow at amino acid positions 95 ( $\mathrm{S}$ vs G) and 129 (V vs M) and the human genotype differs from sheep at 129 ( $M$ vs G). Considering these positions and the lack of differences between cows and deer, if bovine prions can subvert human PrP, there currently appears no reason why cervid prions would also not act similarly. Perhaps subtleties in the protein structures will reveal a potential species barrier.

Table 2 Amino acid positions that show decreased susceptibility to prion disease in deer compared to human, sheep and cow, with the mutation responsible shown in parentheses.

Amino acid positions

\begin{tabular}{llllllll} 
& 95 & 96 & 127 & 129 & 136 & 154 & 170 \\
\hline Human & G & G & G (V) & V(M) & R & M & N \\
Sheep & Q & G & G & M & R & M & N (R) \\
Deer & Q (H) & G (S) & G & M & R & M & N \\
Cow & Q & G & G & M & R & M & N \\
\hline
\end{tabular}


Table 3 Amino acids that comprise the $\beta 2-\alpha 2$ loop in humans, deer, cattle and sheep.

Amino acid position following human PRNP gene

\begin{tabular}{|c|c|c|c|c|c|c|c|c|c|c|c|}
\hline & 165 & 166 & 167 & 168 & 169 & 170 & 171 & 172 & 173 & 174 & 175 \\
\hline Human & $P$ & $\mathbf{M}$ & $\mathrm{D}$ & $\mathbf{E}$ & $Y$ & $\mathbf{S}$ & $\mathrm{N}$ & $Q$ & $\mathrm{~N}$ & $\mathbf{N}$ & $\mathbf{F}$ \\
\hline Sheep & $P$ & $\mathbf{V}$ & $\mathrm{D}$ & $\mathbf{R} / \mathbf{Q}$ & $Y$ & $\mathbf{S}$ & $\mathrm{N}$ & Q & $\mathrm{N}$ & $\mathbf{N}$ & $\mathbf{F}$ \\
\hline Deera & $P$ & V & $D$ & $\mathbf{Q}$ & $\mathrm{Y}$ & $\mathbf{N}$ & $\mathrm{N}$ & Q & $\mathrm{N}$ & $\mathbf{T}$ & $\mathbf{F}$ \\
\hline Cow & $P$ & $\mathbf{V}$ & $\mathrm{D}$ & $\mathbf{Q}$ & $\mathrm{Y}$ & $\mathbf{S}$ & $\mathrm{N}$ & Q & $\mathrm{N}$ & $\mathbf{N}$ & $\mathbf{F}$ \\
\hline
\end{tabular}

Variable positions are bolded.

a. This sequence was observed in white-tailed deer, mule deer, black-tailed deer, Key deer and Coues deer (Zink et al., 2020). See text for sample sizes.

Kurt and Sigurdson (2016) describe potentially subtle differences in amino acid sequences between cervids and humans that could influence cross-species transfer. In particular, they emphasize the $\beta 2-\alpha 2$ loop encoded by amino acid positions 165-175 (Table 3; numbering according to human sequence) and suggest that variation at position 168 could result in incompatible side chain interactions (a steric clash). For example, Kurt and Sigurdson (2016) suggest that E168 and Q168 in human and elk (which have the same sequence as whitetailed deer and mule deer), respectively, results in disruption of a steric zipper, which might preclude the cervid sequence from converting the human PrPC. In Table 3, I show the $\beta 2-\alpha 2$ loops for human, deer, cattle and sheep. If prion disease was in fact transmitted from bovine to human, it is noteworthy that there are amino acid differences at positions 166, and 168, whereas both species are S170; species such as deer possessing N170 are considered prone to CWD. Deer and humans differ at four of the positions in the $\beta 2-\alpha 2$ loop (Table 3), which might function as a species barrier (Kurt and Sigurdson, 2016) via interruptions of steric interactions.

Cullingham et al. (2020) reported amino acid substitutions between CWD susceptible and resistant cervid species (see above) at amino acid positions 15, 97, 170, 174, 203, 205, 215, 215, 232, 237, 246, and 249. Cullingham et al. (2020) singled out positions 170 and 174 within the $\beta 2-\alpha 2$ loop that were significantly associated with resistance to CWD. Cullingham et al. (2020) also noted that sites 96 and 97, within the metal binding region, differ between susceptible and resistant animals and considered this a potential species barrier. In the sample of deer studied by Zink et al. (2020) noted above, none of these 12 amino 
acid positions, nor the two in the metal binding region, was variable, including between white-tailed deer and mule deer with and without CWD. Thus, although variation at these positions might be important across higher taxonomic levels, they do not appear to influence CWD susceptibility within North American deer. Deer and humans differ at positions 15 ( $\mathrm{M}$ vs $\mathrm{T}$ ), 170 ( $\mathrm{N}$ vs S), 174 ( $\mathrm{T}$ vs N), 203 (I vs V), and 232 (- vs M), whereas cow and human differ at 15 ( $M$ vs T), 97 ( $G$ vs $S$ ), 203 (I vs V) and 232 (- vs M). Perhaps these differences make it more difficult for deer to subvert human PrP than for cow.

Although earlier ideas suggested that CWD might have entered North American cervids from penned sheep to mule deer, Harrathi et al. (2019) suggested that substitutions S98T, S173N, N177T and I208M might function as a transmission barrier between sheep and mule deer (positions 170, 173 in Table 3). If these four substitutions function as a sheep - deer species barrier, it might be significant that humans only differ from both white-tailed deer and mule deer at positions 173 and 177 .

\section{Conclusion}

As BSE plays a role in human prion disease, it reveals a considerable phylogenetic leap (Fig. 1), and that genetically rather different proteins are capable of inducing misfolding in other species. If a prion from a cow can interact with a normal protein from a human and cause it to misfold, it would stand to reason that a prion from a deer could elicit a similar reaction in humans, given the similar evolutionary distance. However, CWD has as yet not been detected in humans although in vivo experiments are impossible to perform, except for the ones already in progress in New York and those occurring unwittingly where humans consume venison from pre-clinical-stage deer. Many studies have reviewed variation at multiple amino acid sites thought relevant to CWD species barriers, especially in the $\beta 2-\alpha 2$ loop. However, it is currently unclear which of these amino acid substitutions are most influential in species barriers among sheep, cow, deer and humans (Hwang et al., 2020), or whether genetic factors outside of the genetics of PRNP influence CWD susceptibility in humans. One commonality is that humans eat all three animals. 


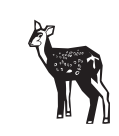

Ethical approval was not required.

Funding This work is based on studies funded by the Nebraska Game and Parks Commission and the Pope and Young Club.

Competing Interest The author declares no conflict of interest.

Acknowledgments I thank Nebraska Game and Parks Commission for supporting my work on CWD. R. Garruto provided helpful comments on the manuscript.

\section{References}

Asante, E.A., Smidak, M., Grimshaw, A., Houghton, R., Tomlinson, A., Jeelani, A., Jakubcova, T., Hamdan, S., Richard-Londt, A., Linehan, J.M., Brandner, S., 2015. A naturally occurring variant of the human prion protein completely prevents prion disease. Nature 522, 478-481.

Bouckaert, R., Heled, J., Kühnert, D., Vaughan, T., Wu, C.H., Xie, D., Suchard, M.A., Rambaut, A., Drummond, A.J., 2014. BEAST 2: a software platform for Bayesian evolutionary analysis. PLOS Comp. Biol. 10, 1-6.

Breydo, L., Uversky, V.N., 2011. Role of metal ions in aggregation of intrinsically disordered proteins in neurodegenerative diseases. Metallomics 3, 1163-1180.

Buchanan, B.L., Zink, R.M., 2020. Submitted. Evolution of transmissible spongiform encephalopathy and the prion protein gene (PRNP) in mammals. J. Mammal. Evol (Submitted).

Calzolai, L., Lysek, D.A., Pérez, D.R., Güntert, P., Wüthrich, K., 2005. Prion protein NMR structures of chickens, turtles, and frogs. Proc. Natl. Acad. Sci. U. S. A. 102, 651-655.

Capobianco, R., Casalone, C., Suardi, S., Mangieri, M., Miccolo, C., Limido, L., Catania, M., Rossi, G., Di Fede, G., Giaccone, G., Bruzzone, M.G., 2007. Conversion of the BASE prion strain into the BSE strain: the origin of BSE? PLoS Pathog. 3, e31.

Cullingham, C.I., Peery, R.M., Dao, A., McKenzie, D.I., Coltman, D.W., 2020. Predicting the spread-risk potential of chronic wasting disease to sympatric ungulate species. Prion 14, 56-66.

Garruto, R.M., Reiber, C., Alfonso, M.P., Gastrich, H., Needham, K., Sunderman, S., Walker, S., Weeks, J., DeRosa, N., Faisst, E., Dunn, J., Fanelli, K., Shilkret, K., 2008. Risk behaviors in a rural community with a known point-source exposure to chronic wasting disease. Environ. Health 17, 31. https://doi. org/10.1186/1476-069X-7-31 
Haase, B., Doherr, M.G., Seuberlich, T., Drögemüller, C., Dolf, G., Nicken, P., Schiebel, K., Ziegler, U., Groschup, M.H., Zurbriggen, A., Leeb, T., 2007. PRNP promoter polymorphisms are associated with BSE susceptibility in Swiss and German cattle. BMC Gen. 8 (1), 15.

Hagenaars, T.J., Melchior, M.B., Windig, J.J., Bossers, A., Davidse, A., van Zijderveld, F.G., 2018. Modelling of strategies for genetic control of scrapie in sheep: the importance of population structure. PLoS One 13 (3), eo1950o9.

Haley, N.J., Merrett, K., Buros Stein, A., Simpson, D., Carlton, A., Mitchell, G., Staskevicius, A., Nichols, T., Lehmkuhl, A.D., Thomsen, B.V., 2019. Estimating relative CWD susceptibility and disease progression in farmed white-tailed deer with rare PRNP alleles. PlosOne 14 (12), eo224342.

Harrathi, C., Fernández-Borges, N., Eraña, H., Elezgarai, S.R., Venegas, V., Charco, J.M., Castilla, J., 2019. Insights into the bidirectional properties of the sheepdeer prion transmission barrier. Mol. Neuro. 56, 5287-5303.

Greenlee, J.J., Nicholson, E.M., 2020 Jan 7. Role of donor genotype in RTQuIC seeding activity of chronic wasting disease prions using human and bank vole substrates. PLoS One 15 (1), eo227487.

Jewell, J.E., Conner, M.M., Wolfe, L.L., Miller, M.W., Williams, E.S., 2005. Low frequency of PrP genotype 225SF among free-ranging mule deer (Odocoileus hemionus) with chronic wasting disease. J. Gen. Virol. 86, 2127-2134.

Johnson, C.J., Herbst, A., Duque-Velasquez, C., Vanderloo, J.P., Bochsler, P., Chappell, R., McKenzie, D., 2011. Prion protein polymorphisms affect chronic wasting disease progression. PLoS One 6 (3), e17450.

Kelley, L.A., Mezulis, S., Yates, C.M., Wass, M.N., Sternberg, M.J., 2015. The Phyre2 web portal for protein modeling, prediction and analysis. Nat. Protoc. 10, 845 .

Konold, T., Spiropoulos, J., Chaplin, M.J., Stack, M.J., Hawkins, S.A.C., Wilesmith, J.W., Wells, G.A.H., 2013. Unsuccessful oral transmission of scrapie from British sheep to cattle. Vet. Rec. https://doi.org/10.1136/vr.101286

Kramm, C., Gomez-Gutierrez, R., Soto, C., Telling, G., Nichols, T., Morales, R., 2019. In vitro detection of Chronic Wasting Disease (CWD) prions in semen and reproductive tissues of white tailed deer bucks (Odocoileus virginianus). PLoS One 14 (12).

Kurt, T.D., Sigurdson, C.J., 2016. Cross-species transmission of CWD prions. Prion 10, 83-91.

Lee, H.-S., Brown, P., Cervanáková, L., Garruto, R.M., Alpers, M.P., Gajdusek, D.C., Goldfarb, L.G., 2001. Increased susceptibility to Kuru of carriers of the PRNP 129 methionine/methionine genotype. J. Infect. Dis. 183, 192-196.

Mathiason, C.K., Powers, J.G., Dahmes, S.J., Osborn, D.A., Miller, K.V., Warren, R.J., Mason, G.L., Hays, S.A., Hayes-Klug, J., Seelig, D.M., Wild, M.A., 2006. Infectious prions in the saliva and blood of deer with chronic wasting disease. Science 314, 133-136.

Mead, S., Uphill, J., Beck, J., Poulter, M., Campbell, T., Lowe, J., Adamson, G., Hummerich, H., Klopp, N., Rückert, I.M., Wichmann, H.E., 2011. Genomewide association study in multiple human prion diseases suggests genetic risk factors additional to PRNP. Hum. Mol. Gen. 8, 1897-19o6. 
Moore, J., Tatum, T., Hwang, S., Vrentas, C., Greenlee, M.H.W., Kong, Q., Nicholson, E., Greenlee, J., 2020. Novel strain of the chronic wasting disease agent isolated from experimentally inoculated elk with LL132 prion protein. Sci. Rep. 10, 1-13.

Nichols, T.A., Fischer, J.W., Spraker, T.R., Kong, Q., VerCauteren, K.C., 2015. CWD prions remain infectious after passage through the digestive system of coyotes (Canis latrans). Prion 9, 367-375.

Olszowy, K.M., Lavelle, J., Rachfal, K., Hempstead, S., Drouin, K., Darcy Ii, J.M., Reiber, C., Garruto, R.M., 2014. Six-year follow-up of a point-source exposure to CWD contaminated venison in an Upstate New York community: risk behaviors and health outcomes 2005-2011. Public Health 128, 860-868.

Osterholm, M.T., Anderson, C.J., Zabel, M.D., Scheftel, J.M., Moore, K.A., Appleby, B.S., 2019. Chronic wasting disease in cervids: implications for prion transmission to humans and other animal species. MBio 10 (4) Aug 27. (eo1091-19).

Race, B., Williams, K., Orrú, C.D., Hughson, A.G., Lubke, L., Chesebro, B., 2018 a. Lack of transmission of chronic wasting disease to Cynomolgus macaques. J. Virol. 92 (eoo550-18).

Race, B., Williams, K., Hughson, A.G., Jansen, C., Parchi, P., Rozemuller, A.J.M., Chesebro, B., 2018b. Familial human prion diseases associated with prion protein mutations Y226X and G131V are transmissible to transgenic mice expressing human prion protein. Acta Neuropathol. Commun. 6, 13.

Rivera-Milla, E., Oidtmann, B., Panagiotidis, C.H., Baier, M., Sklaviadis, T., Hoffmann, R., Zhou, Y., Solis, G.P., Stuermer, C.A., Málaga-Trillo, E., 2006. Disparate evolution of prion protein domains and the distinct origin of Doppeland prion-related loci revealed by fish-to-mammal comparisons. FASEB J. 20, 317-319.

Rongyan, Z., Xianglong, L., Lanhui, L., Xiangyun, L., Fujun, F., 20o8. Evolution and differentiation of the prion protein gene (PRNP) among species. J. Heredit. 99, 647-652.

Sakudo, A., 2019. Chronic wasting disease: current assessment of transmissibility. Curr. Issues Mole. Biol. 36, 13-22.

Scornavacca, C., Belkhir, K., Lopez, J., Dernat, R., Delsuc, F., Douzery, E.J., Ranwez, V., 2019. OrthoMaM v10: scaling-up orthologous coding sequence and exon alignments with more than one hundred mammalian genomes. Mol. Biol. Evol. 36, 861-862.

Selariu, A., Powers, J.G., Nalls, A., Brandhuber, M., Mayfield, A., Fullaway, S., Wyckoff, C.A., Goldmann, W., Zabel, M.M., Wild, M.A., Hoover, E.A., 2015. In utero transmission and tissue distribution of chronic wasting diseaseassociated prions in freeranging Rocky Mountain elk. J. Gen. Virol. 96, 3444-3455.

Slapšak, U., Salzano, G., Ilc, G., Giachin, G., Bian, J., Telling, G., Legname, G., Plavec, J., 2019. Unique structural feathers of mule deer prion protein provide insights into chronic wasting disease. ACS Omega 4 (22), 19913-19924. https:// doi.org/10.1021/acsomega.gbo2824 Nov 15. (eCollection 2019 Nov 26). 
Stevens, D.J., Walter, E.D., Rodríguez, A., Draper, D., Davies, P., Brown, D.R., Millhauser, G.L., 2009. Early onset prion disease from octarepeat expansion correlates with copper binding properties. PLoS Pathog. 5, e1000390. https:// doi.org/10.1371/journal.ppat.1000390

Vázquez-Miranda, H., Zink, R.M., 2020. Geographic distribution of Chronic Wasting Disease resistant alleles in Nebraska, with comments on the evolution of resistance. J. Fish. Wildl. Man. 11, 46-55.

VerCauteren, K.C., Pilon, J.L., Nash, P.B., Phillips, G.E., Fischer, J.W., 2012. Prion remains infectious after passage through digestive system of American crows (Corvus brachyrhynchos). PLoS One 7 (10), e45774 Oct 17.

Waddell, L., Greig, J., Mascarenhas, M., Otten, A., Corrin, T., Hierlihy, K., 2018. Current evidence on the transmissibility of chronic wasting disease prions to humans-a systematic review. Transbound. Emerg. Dis. 65, 37-49.

Williams, E.S., Young, S., 1980. Chronic wasting disease of captive mule deer: a spongiform encephalopathy. J. Wildl. Dis. 16, 89-98.

Zink, R.M., Najar, N., Vázquez-Miranda, H., Buchanan, B.L., Loy, D., Brodersen, B.W., 2020. Geographic variation in the PRNP gene and its promoter, and their relationship to chronic wasting disease in North American deer. Prion 14 (1), 185-192. https://doi.org/10.1080/19336896.2020.1796250 